Jambura Health and Sport Journal

Vol. 2, No. 1, Februari 2020

p-ISSN: 2654-718X, e-ISSN: 2656-2863

\title{
RELAKSASI FINGER HOLD UNTUK PENURUNAN NYERI PASIEN POST OPERASI APPENDEKTOMI
}

\section{RELAXATION FINGER HOLD FOR REDUCTION OF POST-OPERATIVE PATIENT APPENDEKTOMY}

\author{
Ahmad Aswad \\ Jurusan Keperawatan Poltekkes Kemenkes Gorontalo \\ Kontak Penulis: ahmadaswad806@gmail.com
}

\begin{abstract}
ABSTRAK
Penyakit usus buntu adalah peradangan yang terjadi pada usus buntu atau appendisitis. Penelitian ini bertujuan untuk mengetahui pengaruh teknik relaksasi Finger Hold terhadap penurunan nyeri pada pasien post operasi appendiktomi. Desain yang digunakan dalam penelitian ini adalah quasy experiment dengan teknik one group pretest dan posttest design tanpa kelompok kontrol. Pengambilan sampel dilakukan dengan metode non probability sampling melalui teknik accidental sampling sebanyak 32 pasien post operasi appendiktomi. Alat ukur skala nyeri Visual Analog Scale (VAS). Analisis data meliputi univariat dan bivariat menggunakan uji wilcoxon. Hasilnya, sebelum dilakukan teknik relaksasi Finger Hold skala nyeri sangat berat $(53,1)$ dan berat $(46,9)$. Setelah dilakukan teknik relaksasi Finger Hold skala nyeri sangat berat $(25,0)$ dan nyeri berat $(75,0)$. Hasil tersebut membuktikan bahwa perlunya teknik relaksasi Finger Hold untuk mengurangi nyeri yang dirasakan pada pasien post operasi appendiktomi.
\end{abstract}

Kata kunci: relaksasi; finger hold; nyeri; appendiktomi

\begin{abstract}
Appendicitis is inflammation that occurs in the appendicitis. This study aims to determine the effect of Finger Hold relaxation techniques on pain reduction in post operative appendectomy patients. The design used in this study was quasy experiment with one group pretest and posttest design techniques without a control group. Sampling was done by non probability sampling method through accidental sampling technique as many as 32 patients post appendectomy surgery. Visual Analog Scale (VAS) pain scale. Data analysis included univariate and bivariate using the Wilcoxon test. As a result, prior to the Finger Hold relaxation technique the pain scale was very heavy (53.1) and severe (46.9). After the Finger Hold relaxation technique was performed, the pain scale was very severe (25.0) and severe pain (75.0). These results prove that the need for Finger Hold relaxation techniques to reduce pain felt in patients with post operative appendectomy.
\end{abstract}

Keywords: relaxation; finger hold; pain; appendectomy 


\section{PENDAHULUAN}

Penyakit usus buntu adalah peradangan yang terjadi pada usus buntu atau appendicitis (Anggarani., et al, 2012). Usus buntu merupakan organ berbentuk kantong kecil dan tipis, berukuran 5 hingga $10 \mathrm{~cm}$ yang terhubung dengan usus besar. Saat menderita radang usus buntu, penderita dapat merasa nyeri di perut kanan bawah. Jika dibiarkan infeksi menjadi serius dan menyebabkan usus buntu pecah, sehingga menimbulkan keluhan nyeri yang hebat hingga membahayakan nyawa penderitanya. Nyeri merupakan pengalaman sensorik dan emosional yang tidak menyenangkan akibat kerusakan jaringan, baik aktual maupun potensial atau yang digambarkan dalam bentuk kerusakan tersebut (Bahrudin, 2017).

Radang usus buntu dapat terjadi pada semua usia, namun paling sering pada usia 10 sampai 30 tahun. Penyakit usus buntu bisa disebabkan sumbantan pada usus, baik sebagian atau total. Radang pada usus buntu yang menyeluruh merupakan kondisi darurat dan perlu segera ditangani dengan tindakan operasi.

Hasil wawancara peneliti dengan empat orang klien yang sedang dirawat inap dengan post operasi appendiktomi di Ruang rawat inap bedah RSUD Prof, Dr. H. Aloei Saboe Kota Gorontalo, dua orang mengatakan bahwa mulai merasakan nyeri dua sampai empat jam setelah pembedahan dan dua orang lainnya menyatakan nyeri yang sangat berat tetapi belum dilakukan tindakan nonfarmakologis.

Pemulihan pasien post pembedahan membutuhkan waktu rata-rata 72,45 menit sehingga pasien akan merasakan nyeri yang hebat rata-rata pada dua jam pertama sesudah operasi karena pengaruh obat anastesi sudah hilang. Nyeri merupakan suatu mekanisme proteksi bagi tubuh, timbul ketika jaringan sedang rusak, dan menyebabkan individu tersebut bereaksi terhadap rasa nyeri.

Strategi penatalaksanaan nyeri atau lebih dikenal dengan manajemen nyeri adalah suatu tindakan untuk mengurangi nyeri. Manajemen nyeri non farmakologi perlu dilakukan oleh perawat di ruang bedah meskipun banyak kendala beban kerja yang tinggi (Ilmiasih, 2013). Dalam dunia keperawatan, Perawat memiliki peran penting dalam mengatasi nyeri. Proses keperawatan ini dilakukan untuk meminimalisir kerusakan saraf yang dianggap sebagai salah satu penyebab nyeri pasca operasi (Damayati \& Wiyono, 2019). Manajemen pereda nyeri nonfarmakologis merupakan tindakan menurunkan respon nyeri. Strategi melakukan intervensi keperawatan nonfarmakologis merupakan tindakan independen dari seorang perawat dalam mengatasi respon nyeri klien.

Manajemen nyeri sangat beragam salah satunya adalah teknik relaksasi genggam jari (Finger Hold). Teknik relaksasi Finger Hold merupakan teknik relaksasi yang sederhana dan mudah dilakukan oleh siapapun yang berhubung dengan jari tangan serta aliran energi di dalam tubuh. Teknik relaksasi genggam jari dan nafas efektif dalam menurunkan nyeri haid

Mengenggam jari sambil menarik nafas dalam/relaksasi dapat mengurangi nyeri dan menyembuhkan ketegangan fisik dan emosi. Teknik tersebut nantinya dapat menghangatkan titiktitik keluar dan masuknya energi pada median (energi channel) yang terletak pada jari tangan kita, sehingga mampu memberikan rangsangan secara reflex/spontan pada saat genggaman. Rangsangan yang didapat nantinya akan mengalir gelombang menuju ke otak, kemudian dilanjutkan ke saraf pada organ tubuh yang mengalami gangguan, sumbatan di jalur energi menjadi lancar.

\section{METODE PENELITIAN}

Desain Penelitian yang digunakan adalah quasi experiment dengan pendekatan pretest postest tanpa kelompok kontrol. Quasi Eksperimen menurut Sugiyono (2014) adalah desain yang digunakan karena pada kenyataannya sulit mendapatkan kelompok kontrol yang digunakan untuk 
penelitian. Penelitian ini merupakan penelitian kuantitatif, dengan melakukan beberapa kali pengukuran. Penelitian ini menerapkan pengukuran dan intervensi secara berulang sebanyak dua kali. Populasi dalam penelitian ini adalah semua pasien yang telah dilakukan post operasi appendiktomi yang mengalami nyeri akut di ruang rawat inap bedah RSUD Prof. Dr. H. Aloei Saboe. Pengambilan sampel adalah menggunakan non-probability sampling dengan teknik accidental sampling, sebanyak 32 responden. Instrumen penelitian menggunakan pedoman lembar observasi sebelum dan sesudah perlakuan Finger Hold pada kelompok intervensi.

Pasien dilakukan teknik relaksasi genggam jari Finger Hold selama 15 menit terhadap penurunan nyeri pada pasien yang telah dilakukan tindakan post operasi appendiktomi. Analisis data meliputi univariat dan bivariat dengan menggunakan uji statistik paired T-test.

\section{HASIL PENELITIAN}

Tabel 1. Distribusi Frekuensi Karakteristik Responden Berdasarkan Umur.

\begin{tabular}{cccc}
\hline No & Umur & Jumlah & Presentase $(\%)$ \\
\hline 1 & $12-20$ & 18 & 56.3 \\
\hline 2 & $21-29$ & 7 & 21,9 \\
\hline 3 & $30-38$ & 3 & 9,4 \\
\hline 4 & $39-47$ & 2 & 6,3 \\
\hline 5 & $48-55$ & 2 & 6,3 \\
\hline & Total & 32 & 100 \\
\hline
\end{tabular}

Sumber: Data Primer

Berdasarkan data diatas menunjukan distribusi umur responden yang paling banyak yaitu 12-20 tahun yaitu berjumlah 18 orang $(56,3 \%)$.

Tabel 2. Distribusi Frekuensi Karakteristik Responden Berdasarkan Jenis Kelamin.

\begin{tabular}{cccc}
\hline No & Jenis Kelamin & Jumlah & Presentase (\%) \\
\hline 1 & Laki-laki & 19 & 59,37 \\
\hline 2 & Perempuan & 14 & 41,63 \\
\hline & Total & 32 & 100 \\
\hline
\end{tabular}

Sumber: Data Primer

Berdasarkan data diatas menunjukan distribusi jenis kelamin responden yang paling tinggi adalah laki-laki yaitu berjumlah 19 orang $(59,37 \%)$.

Tabel 3. Distribusi Frekuensi Karakteristik Responden Berdasarkan Pendidikan.

\begin{tabular}{cccc}
\hline No & Pendidikan & Jumlah & Presentase (\%) \\
\hline 1 & SD & 2 & 6,3 \\
\hline 2 & SLTP & 9 & 28,1 \\
\hline 3 & SMA & 15 & 46,9 \\
\hline 4 & Diploma & 4 & 12,5 \\
\hline 5 & Sarjana & 2 & 6,3 \\
\hline & Total & 32 & 100 \\
\hline
\end{tabular}

Sumber: Data Primer 
Berdasarkan data diatas menunjukan distribusi pendidikan responden paling banyak adalah SMA berjumlah 15 orang $(46,9 \%)$.

Tabel 4. Distribusi Frekuensi Berdasarkan Skala Nyeri Sebelum dilakukan Teknik Relaksasi Finger Hold.

\begin{tabular}{cccc}
\hline No & Skala Nyeri & $(\mathrm{N})$ & Presentase $(\%)$ \\
\hline 1 & Tidak ada nyeri: 0 & 0 & 0 \\
\hline 2 & Nyeri ringan: $1-2$ & 0 & 0 \\
\hline 3 & Nyeri sedang: $3-4$ & 0 & 0 \\
\hline 4 & Nyeri berat: $5-6$ & 15 & 46,9 \\
\hline 5 & Nyeri sangat berat: $7-8$ & 17 & 53,1 \\
\hline 6 & Nyeri buruk: $9-10$ & 0 & 0 \\
\hline & Total & 32 & 100
\end{tabular}

Sumber: Data Primer

Berdasarkan data atas menunjukan distribusi frekuensi skala nyeri sebelum pemberian Teknik Relaksasi Finger Hold yang tertinggi adalah Nyeri sangat berat skala 7-8 berjumlah 17 orang $(53,1 \%)$.

Tabel 5. Distribusi frekuensi berdasarkan Skala Nyeri Sesudah Pemberian Teknik Relaksasi Finger Hold.

\begin{tabular}{cccc}
\hline No & Skala Nyeri & Jumlah & Presentase $(\%)$ \\
\hline 1 & Tidak ada nyeri: 0 & 0 & 0 \\
\hline 2 & Nyeri ringan: $1-2$ & 0 & 0 \\
\hline 3 & Nyeri sedang: $3-4$ & 0 & 0 \\
\hline 4 & Nyeri berat: $5-6$ & 24 & 75 \\
\hline 5 & Nyeri sangat berat: $7-8$ & 8 & 25 \\
\hline 6 & Nyeri buruk: $9-10$ & 0 & 0 \\
\hline & Total & 32 & 100 \\
\hline
\end{tabular}

Sumber: Data Primer

Berdasarkan data diatas menunjukan distribusi frekuensi skala nyeri sesudah pemberian teknik relaksasi Finger Hold tertinggi adalah Nyeri berat: 5-6 berjumlah 24 orang (75\%).

Tabel 6. Analisis Selisih Skala Nyeri (VAS) Sebelum dan Sesudah Teknik Finger Hold

\begin{tabular}{lccccc}
\hline Variabel & Mean & Selisih Mean & SD & Min - Maks & Nilai P \\
\hline Skor Skala Nyeri & 6.63 & 16,50 & 0.907 & $5-8$ & $0.000^{*}$ \\
Pre & & & & & \\
\cline { 1 - 1 } $\begin{array}{l}\text { Skor Skala Nyeri } \\
\text { Post }\end{array}$ & 2,16 & & 0.767 & $1-4$ & \\
\hline
\end{tabular}

Sumber: Data Primer

Berdasarkan data hasil penelitian diketahui selisih skala nyeri sebelum dilakukan teknik relaksasi Finger Hold adalah 6,63 dan setelah dilakukan teknik relaksasi Finger Hold menjadi 2,16 
dengan selisih yang didapatkan yaitu 16,50. Hasil uji non parametrik t dependen yaitu dengan menggunakan Uji Wilcoxon didapatkan pvalue $0,000(<0,05)$ artinya ada perbedaan yang signifikan skala nyeri sebelum dan sesudah diberikan teknik relaksasi Finger Hold.

\section{PEMBAHASAN}

Prevalensi skala nyeri setelah dilakukan teknik relaksasi Finger Hold adalah 16,0. Penurunan skala nyeri terjadi karena responden sudah diberi intervensi teknik relaksasi Finger Hold selama 10-20 menit. Nyeri sering timbul sebagai manifestasi klinis pada suatu proses patologis, dimana nyeri tersebut memrovokasi saraf - saraf sensorik nyeri menghasilkan reaksi ketidaknyamanan, distres, atau penderitaan (Mardana \& Aryasa, 2017).

Teknik relaksasi Finger Hold adalah melibatkan genggaman jari dan pengaturan nafas. Pada setiap anggota tubuh terdapat aliran energi, dimana pada genggaman jari ini aliran energi dipersepsikan sebagai stimulus untuk rileks. Stimulus ini mengaktifkan transmisi serabut saraf Abeta yang lebih besar dan cepat, menurunkan transmisi nyeri melalui serabut $\mathrm{C}$ dan delta-A yang berdiameter lebih kecil, proses ini menghambat stimulus nyeri. Jika tidak ada informasi nyeri yang disampaikan ke otak, maka tidak ada nyeri yang dirasakan. Dengan pengaturan nafas melalui genggaman jari, ketegangan serta kecemasan pasien dapat dikontrol,pasien akan merasa rileks dan santai yang selanjutnya akan menimbulkan tingkat kenyamanan yang lebih baik sehingga intensitas nyeri dapat menurun. Perlakuan relaksasi genggam jari akan menghasilkan impuls yang dikirim melalui serabut saraf aferen non nosiseptor. Serabut saraf non nosiseptormengakibatkan "pintu gerbang" tertutup sehingga stimulusnyeri terhambat dan berkurang (Pinandita., et al. 2012).

Analisis statistika dengan menggunakan uji non parametrik $t$ dependen yaitu dengan menggunakan uji Wilcoxon didapatkan pvalue 0,000. Skala nyeri pada responden sebelum dilakukan perlakuan teknik relaksasi Finger Hold yakni 6,63 dan setelah diberian perlakuan teknik relaksasi Finger Hold menjadi 2,16 dari hal ini dapat menunjukan bahwa setelah diberikan perlakuan teknik relaksasi Finger Hold nilai mean turun dari sebelum diberikan perlakuan.

Menurut Liana (2008) relaksasi genggam jari (Finger Hold) adalah sebuah teknik relaksasi yang sangat sederhana dan mudah dilakukan oleh siapapun, yang berhubungan dengan jari tangan serta aliran energi di dalam tubuh kita. Menggenggam jari sambil menarik napas dalam (relaksasi) dapat mengurangi dan menyembuhkan ketegangan fisik dan emosi. Penelitian oleh Agustin (2012) tentang "Pengaruh Teknik Relaksasi Genggam Jari Terhadap Penurunan Intensitas Nyeri Pada Pasien Post Operasi Appendiktomi", bahwa teknik relaksasi genggam jari dapat menurunkan intensitas nyeri pada pasien post operasi Appendiktomi.

\section{KESIMPULAN}

Dari penelitian ini dapat diungkapkan bahwa penurunan skala nyeri pada pasien post operasi appendiktomi, teknik relaksasi Finger Hold ini nyeri yang dirasakan oleh responden menjadi berkurang. Perlunya seorang perawat dalam menguasai teknik relaksasi Finger Hold ini bukan hanya untuk mengurangi nyeri pada penurunan nyeri pasien post operasi appendektomi saja. Akantetapi bisa juga untuk mengatasi nyeri pada pasien-pasien dengan gejala nyeri yang lainnya.

\section{REFERENSI}

Agustin, E. K. W. (2014). Pengaruh Teknik Relaksasi Genggam Jari Terhadap Penurunan Nyeri pada Pasien dengan Post Operasi Apendiktomi di Eka Hospital BSD. Skripsi. Fakultas Ilmu-Ilmu Universitas Esa Unggul. Jakarta. 
Anggarani, D, N., Kartika, D., Novitasari, D, A., Nasution, M, N, A., Arindita, N, D., Rahfiludin. (2012). Table Kroasia" Tablet Krokot Berkhasiat, Inovasi Effervescent Dari Tanaman krokot (Portulacaoleracea L) Sebagai Alternatif Minuman Bersuplemen Bagi Penderita radang Usus Buntu. Jurnal Ilmiah Mahasiswa Gizi Kesehatan Masyrakat Fakultas Kesehatan Masyarakat Universitas Diponegoro, 2, (2), 91-96

Bahrudin, M. (2017). Patofisiologi Nyeri (Pain). Fakultas Kedokteran Universitas Muhammadiyah Malang (E-journal), 13(1), 7-13

Damayanti, R.., I., \& Wiyono, J. (2019). Differences Pain Intensity Between Back Massage Therapy And Finger Hold Relaxation In Patien Post Laparatomy. Jurnal Keperawatan Terapan (E-Journal), 5(1), 10 - 21. doi:10.31290/jkt.v5i1.671

Ilmiasih, R. (2013). Promosi Manajemen Nyeri Nonfarmakologi oleh Keluarga pada Pasien Post Operasi di Ruang BCH RRUPN Dr.Ciptomangunkusumo Jakarta. JURNAL KEPERAWATAN. 4(2), 116-121. https://doi.org/10.22219/jk.v4i2.2361

Liana, E. (2008). Teknik Relaksasi: Genggam Jari untuk Keseimbangan Emosi. http://www.pembelajar.com/teknik relaksasgenggam-jari untuk keseimbangan emosi (Diakses 21 Oktober 2016).

Mardana, I, K, R, P., \& Aryasa, T. (2017). Penilaian Nyeri. SMF/Bagian Anestesiologi dan Terapi Intensif Fakultas Kedokteran Universitas Udayana RSUP Sanglah Denpasar.

Pinandita, I., E. Purwati, dan B. Utoyo. (2012). Pengaruh Tehnik Releksasi Genggam Jari Terhadap Penurunan Intensitas Nyeri Pada Pasien Post Operasi Laparatomi. Jurnal.

Ramadina, S., Utami, S., \& Jumaini. (2014). Efektifitas Teknik Relaksasi Genggam Jari dan Nafas dalam Terhadap Penurunan Dismenore. Jurnal Online Mahasiswa Program Studi Ilmu Keperawatan Universitas Riau, 1(1), 1-8.

Sugiyono. (2014). Metodologi Penelitian Kuantitatif, Kualitatif, Dan R\&D. Bandung: Alfabeta. 